\title{
O militarismo no Uruguai ${ }^{1}$
}

Militarism in Uruguay

\author{
Suzeley Kalil MATHIAS ${ }^{\bullet}$ \\ Tiago Pedro VALES ${ }^{\bullet \bullet}$
}

Resumo: Desde muito cedo, ainda no século XIX, o Uruguai vem desenvolvendo uma política democrática baseada na educação, ao que pode ser creditado o afastamento das suas Forças Armadas da participação política. Entretanto, o sistema partidário, essencial para o desenvolvimento da democracia, não foi suficientemente forte para manter os militares completamente afastados do governo, vivendo o país momentos de militarismo. O propósito deste trabalho é repassar o processo político uruguaio destacando os momentos em que as Forças Armadas estiveram mais próximas do poder. Entende-se que compreender o desenvolvimento da política no país é essencial para, já em outro trabalho, avaliar como a educação, especialmente a oferecida às forças armadas, influencia o desenvolvimento e consolidação de uma cultura democrática.

Palavras-chave: Forças Armadas; Democracia; Militarismo; Uruguai.

Abstract: Very early in the nineteenth century, Uruguay has been developing a democratic politics based on education, to which can be credited the removal of her Armed Forces from political participation. However, the party system, essential for the development of democracy, was not strong enough to keep the militaries completely out of the government, the country living moments of militarism. The purpose of this work is to pass the Uruguayan political process highlighting the moments when the Armed Forces were closer to power. It is understood that understand the development of policy in the country is essential, and in another work, evaluate how education, especially the one offered to the Armed Forces, influences the development and consolidation of a democratic culture.

Keywords: Armed Forces; Democracy; Militarism; Uruguay.

"O Exército é um leão que se deve manter enjaulado para soltá-lo apenas no dia da batalha"

Sarmiento

\section{Introdução}

Pode-se dizer que os estudos sobre forças armadas, defesa e temas afins vêm crescendo no Brasil e na América Latina, deixando de ser considerado tema maldito pela academia. Exemplo desse crescimento pode ser encontrado na quantidade de trabalhos anualmente apresentados em diferentes congressos - desde os de geógrafos até os de engenharia -, mas principalmente por

\footnotetext{
- Professora Livre Docente - Departamento de Educação, Ciências Sociais e Política Internacional e do Programa de Pós-graduação em História - Faculdade de Ciências Humanas e Sociais - UNESP - Campus de Franca - Av. Eufrásia Monteiro Petráglia, 900, CEP: 14409-160, Franca, SP, Brasil. Pesquisadora do GEDES - Grupo de Estudos de Defesa e Segurança Internacional da UNESP, campus de Franca. E-mail: suzeley@uol.com.br

- Mestrando - Programa de Pós-Graduação em História - Faculdade Ciências Humanas e Sociais - UNESP - Univ. Estadual Paulista - Campus de Franca - Av. Eufrásia Monteiro Petráglia, 900, CEP: 14409-160, Franca, SP, Brasil. Bolsista FAPESP. Pesquisador do GEDES - Grupo de Estudos de Defesa e Segurança Internacional da UNESP, campus de Franca. E-mail: tpvales@gmail.com
} 
aqueles inscritos nos encontros da Associação Brasileira de Estudos da Defesa (ABED) que em 2010, promoveu seu IV congresso com mais de 200 inscritos; não é demais dizer que a própria organização da ABED mostra que os estudos na área vêm crescendo. Entretanto, esse movimento não foi acompanhado nem pelos órgãos castrenses ou estatais e nem pelo mercado acadêmico editorial: poucas são as revistas que aceitam trabalhos sobre o tema e não existe nenhuma publicação nacional especializada - pior, a revista editada por muitos anos pela Flacso-Chile, Fuerzas Armadas y Sociedad, deixou de circular há alguns anos. Assim, levantar dados, estudar alguns temas ou promover a divulgação de outros, continua exigindo um trabalho hercúleo dos pesquisadores. Por isso, a promoção de um Dossiê cujo tema é Militarismo deve ser efusivamente festejada. Isso mostra o compromisso da historiografia brasileira com os temas de relevância social, ao mesmo tempo em que comprova a capacidade de seus pesquisadores e entidades de continuarem afinados com seu tempo.

Nossa intenção aqui não é laurear esta ou aquela publicação, o que não deve impedir de registrar nossa boa impressão sobre este Dossiê. Nosso objetivo neste trabalho é descrever a evolução da política no Uruguai para, no futuro, avaliar a relação entre educação militar e democracia no país nos anos mais recentes. É bom lembrar a educação como um elemento central para compreender o Uruguai, sua sociedade e sua política. Há quem diga que a relação entre educação e política sempre foi conflitiva (SEMPOL, 2008, p. 97), conferindo à primeira um caráter quel chamamos estratégico.

Justamente por considerarmos a educação como uma variável estratégica para a compreensão de qualquer processo político, elegemos a relação entre a educação militar e a democracia como a variável mais importante para compreender o processo político atual na região sul-americana. Entretanto, em respeito ao leitor, não é possível tratar esta relação sem antes conhecer a constituição política de cada país. Ressalte-se que ao iniciarmos as pesquisas a respeito, notamos que os estudos específicos sobre cada país da região são tão raros quanto as análises sobre as forças armadas na academia. Por isso, decidimos que o objetivo perseguido neste texto será revisitar o desenvolvimento das forças armadas (FFAA) no Uruguai paralelamente à construção do seu Estado. Assim, a partir de nosso estranhamento com o tema proposto, isto é, Militarismo, acompanhamos os principais acontecimentos da política uruguaia desde o século XIX até o início do século XXI. Tal discussão será, obviamente, superficial e para alguns até desnecessária. Defendemos essa revisão como essencial porque, ao iniciarmos nossas pesquisas, percebemos que não apenas os temas militares são desconhecidos, mas também pouco ou quase nada conhecemos de nossos vizinhos mais próximos. De fato, as pesquisas sobre os fenômenos políticos do e no Continente tem privilegiado estudos sobre os Estados Unidos da América do Norte e, em menor medida, sobre a Argentina. 
Mas o que significa estranhar-se quanto ao tema Militarismo? Imediatamente pensamos: será que é possível escrever algo sobre o universo político dos países Sul Americanos? Embora todos, ou quase todos, tenham seu passado marcado pela presença castrense na política, esta poderia ser classificada como militarismo? Este questionamento surgiu também porque o fenômeno de apropriação do poder pelos militares, bem como os regimes subsequentes, já foi avaliado sob o termo militarização (MATHIAS, 2004). Militarismo e militarização seriam, então, termos que comportavam o mesmo significado?

Para solucionar a questão confrontamos ambos os termos. Militarismo, segundo Pasquino (1986), comporta vários significados, dentre os quais, “o Militarismo é uma degeneração do modo militar de agir” (p. 749). Já militarização diz respeito a um conjunto menor de fenômenos e, ao mesmo tempo refere-se à presença do militar nas instituições políticas, seja esta presença física (ocupação de cargos), doutrinária (interferência da doutrina militar nas políticas públicas) ou valorativa (o ethos militar é igual ao ethos político) (MATHIAS, 2004, pp. 25-26).

Dado o significado de cada termo, e entendendo militarismo como qualquer fenômeno que fuja ao quefazer militar, às atividades ligadas à defesa nacional na guerra, adotamos essa definição para analisar a situação do Uruguai do final do século $\mathrm{XX}$, pois acreditamos que o fenômeno político ali apresentado diz respeito justamente ao desvio dos militares de sua profissão. Isso não descarta a possibilidade de momentos de militarização, de presença militar conforme acima definido, ao longo do processo de militarismo uruguaio, mas a inversa não é verdadeira. Em outras palavras, pode existir militarização sob momentos de militarismo, mas não existe uma concomitância necessária entre os dois fenômenos.

Objetivamos, portanto, revisitar a história da formação do Estado no Uruguai, enfatizando a participação dos militares em tal processo. Nesse texto, seguimos cronologicamente a caminhada política uruguaia, sublinhando aqueles momentos nos quais as Forças Armadas tiveram maior proximidade do centro do poder político. O período de análise se concentra no final do século XIX, quando o Exército uruguaio se apresenta pela primeira vez na história como uma instituição pública, e nos anos 70-80 do século XX, quando as FFAA deixam de ser um órgão do Estado e assumem o governo. Entendemos essa revisão como necessária para, num segundo momento, estudar como a educação militar influencia a democracia. Registramos, todavia que, dado o espaço que temos aqui, nossa avaliação se restringirá ao primeiro objetivo, isto é, ao processo de construção das instituições políticas no Uruguai e à participação dos militares nesse processo.

Seguindo a cronologia da política uruguaia, dividimos o texto em quatro partes. Na primeira, descrevemos os acontecimentos que levaram à construção do Estado nacional e o desenvolvimento de um sistema político peculiar, com o poder executivo central colegiado e baixa interferência militar na política. A essas peculiaridades, junta-se a implementação de um sistema de ensino que 
garante a educação à quase universalidade dos cidadãos ainda nos primórdios do século XX. Já na segunda, dedicamo-nos a analisar o período imediatamente anterior ao golpe de Estado, apontando para as características desse fenômeno, o qual vai se moldando com a passagem do tempo. É nesse momento que se organiza a máquina repressiva do Estado: uma violência que antecede o próprio golpe e a convivência entre repressão legal e clandestina.

O desenvolvimento das bases do regime burocrático-autoritário, fundamentalmente suas raízes na Doutrina de Segurança Nacional e na eliminação de qualquer oposição ao regime, o que aconteceu no Uruguai no primeiro lustro dos 1970, é discutido na terceira parte do texto. Nele, buscamos apontar as distinções entre a participação militar no processo político uruguaio relativamente aos demais países da região, em especial seus dois grandes vizinhos, Argentina e Brasil. Já na quarta e última parte, a mais extensa de todas, acompanhamos a culminância do militarismo no Uruguai. Defendemos que as FFAA nesse processo não apenas queriam construir uma nova ordem, mas sim erigir, pela força uma nova cultura política, cujo ponto central estaria na superação do bipartidarismo. Apontamos também seu insucesso nesta empreitada, o que mostra a fortaleza do regime político, com seus partidos e conflitos.

\section{O Nascimento do Estado}

Os conhecedores da história do Uruguai são unânimes em afirmar que não é possível compreender o processo político deste país sem levar em consideração duas particularidades. A primeira é geopolítica: o país é um istmo entre dois grandes, Argentina e Brasil. Para se impor, restava à pequena nação buscar apoio em países externos ao subcontinente. A segunda encontra-se na formação política nacional do início do século XX, com a chegada de José Batlle y Ordóñez à presidência da República (1902).

No esteio dos processos de independência da América do Sul, o Uruguai alcança a sua entre 1825, quando vence o conflito contra o Brasil, e 1930, neste momento com a mediação da Inglaterra. A participação da então força hegemônica da época na criação do país foi necessária, segundo os relatos históricos, pela característica geopolítica mencionada acima, o que levou o país a sempre orbitar em torno da Inglaterra e, já no século XX, dos EUA, para contrabalançar o poder dos países com os quais o Uruguai faz fronteira.

A geopolítica, entretanto, não foi capaz de garantir o afastamento militar do cenário político que, à semelhança de seus vizinhos hispânicos, vivenciou o caudilhismo como alicerce de formação do país ao longo do século XIX. Assim, foi sob o governo de um militar, o coronel Lorenzo Latorre (1876-1902), que se promoveram as reformas que criaram as condições para a modernização do país. O principal feito desta gestão foi sua reforma educacional que, sob a batuta do ex-presidente 
José Pedro Varela, culminou na Ley de Enseñanza Común (1877), instituindo o ensino gratuito, obrigatório e universal no país, capaz de constituir uma marca indelével em todo o futuro do país.

Concomitantemente à formação do Estado, formam-se dois partidos, cada um deles representando uma facção das elites apoiadoras de diferentes caudilhos. O partido Colorado representava os setores urbanos, ligados à capital, Montevidéu. Já o partido Blanco, representa os setores agrários e tendia a ser mais próximo dos setores mais conservadores, à semelhança da elite que se formava nos países vizinhos.

Já no século XX, chega ao governo José Batlle y Ordóñez, representante do Partido Colorado e vencedor da última investida significativa do Partido Blanco, datada de 1904, estabelecendo a hegemonia colorada, cujo partido permanece no poder até $1930 .^{2}$ Na primeira gestão de Batlle (1903-1907), consolidam-se as reformas já implantadas - como as trabalhistas, iniciadas a partir de 1875 -, ao mesmo tempo que outras são promovidas, como o ensino laico (1905) e a Lei do divórcio (1907), mesmo ano no qual o presidente uruguaio pede a intervenção de Haia para arbitrar conflitos internacionais, fazendo com que apelar para a arbitragem internacional fosse se tornando o grande eixo da política externa do país (LOPEZ, 1995).

O sucesso de Batlle se confirma com seu retorno ao governo em 1911, para um novo mandato que duraria até 1915. Neste segundo governo, a grande novidade foi a organização do poder central em forma colegiada, por meio do Conselho Administrativo, garantindo à oposição 1/3 de participação no poder executivo central. Esta medida, na maioria das vezes condenada, representou a paz definitiva para a política uruguaia, ao mesmo tempo que criava uma cultura conciliatória e favorecedora dos partidos (SIERRA, 1985, p. 143). Em razão disso, por exemplo, neste país os partidos socialistas e comunistas são legalizados e participam de eleições durante boa parte do século XX antes, obviamente, da implantação do governo burocrático-autoritário, em 1973.

No seu segundo mandato, Batlle aprofunda mudanças na legislação trabalhista estabelecendo jornada diária de trabalho, descanso semanal remunerado, direito a férias, proibição do trabalho infantil e pagamento de aposentadoria para os inválidos - , derrotando no nascedouro as lideranças sindicais; modifica a legislação educacional, especialmente a referente ao ensino médio e técnico - que passa a ser obrigatório - e ao ensino superior. Portanto, assim começa a despontar o que viria a ser o primeiro welfare state nas Américas, daí porque recebeu a alcunha de Suíça Americana (ARTEAGA, 1995). ${ }^{3}$

As ideias que José Batlle defendia, portanto, visavam o desenvolvimento do país, com controle central da economia, estabelecendo monopólios estatais em conjunto com uma corrente de leis de cunho social que resultaria em uma sociedade de classe média protegida por um Estado intervencionista e distribuidor dos ganhos, ao mesmo tempo que contariam com uma economia sólida, que migrava paulatinamente do setor agrário exportador para o urbano de serviços, ao qual 
se subordinava o desenvolvimento industrial. Tais mudanças, mormente na economia, tiveram repercussões positivas tanto no âmbito interno quanto no plano internacional. A respeito das esferas de poder uruguaias, o batllismo significou a consolidação da vitória do Partido Colorado, no poder desde 1865, constituindo o centro político-ideológico em torno do qual gravitou a modernização do país.

Para as forças armadas, o batllismo significava o completo alijamento da instituição do processo político, o que representava ainda menores vínculos daquelas com a sociedade civil, a qual reconhecia as Forças Armadas como mais um órgão burocrático, além de ser uma fonte relevante de emprego público. Já a educação precoce garantiu não apenas a formação da nação, mas também a modernização política, com a vigência da democracia mais ou menos organizada, que prezava a representação partidária, inclusive da minoria. Assim, já no início do século XX, nas palavras de Rilla (2004, p. 189), repetindo Germán Rama, o Uruguai

É uma sociedade de imigrantes, é uma sociedade onde todos os processos de mobilidade social realizaram-se através da escola. A unidade nacional se fez com as escolas. Falávamos todos os idiomas, mas a escola fez com que todos se fundissem [no espanhol]. Ela foi a grande máquina que erigiu o Uruguai [...] Neste país houve uma época de guerras civis em que se empregavam facas para a degola. Apareceu José Pedro Varela que fez uma proposta incrível: façamos uma nação democrática, trabalhadora, com mobilidade social por meio da escola; só assim seremos uma nação [...] Este país se formou a punta de escuelas.

Talvez esteja na universalização do ensino ${ }^{4}$ a melhor explicação para o afastamento das Forças Armadas do poder político (LOPEZ, 1995), o que não impediu, entretanto, que se instalassem no país dois períodos ditatoriais. Também o precoce processo de profissionalização das Forças Armadas parece ter contribuído para o alijamento castrense da política. A profissionalização do Exército e da Armada iniciou-se ainda no século XIX, ao fim da Guerra do Paraguai. Entre 1870 e 1895, foram criadas as noções hierárquicas dentro das Forças Armadas, organizaram-se os corpos de exército e buscou-se superar o recrutamento "no laço", ainda que todas essas mudanças só fossem regulamentadas tempos depois. Tais mudanças culminaram com a criação da Academia Militar, em 1895, primeira instituição dedicada à formação do profissional de armas.

Ressalte-se que se o Uruguai passou por duas ditaduras, ambas foram impulsionadas por governos democraticamente eleitos. A primeira, entre 1933 e 1942, foi implementada pelo então presidente Gabriel Terra (1933-38) e continuada na chamada dictablanda, sob Alfredo Baldomir (1938-42). No desenvolvimento desta, a participação militar praticamente inexistiu. Já a segunda, ainda que desencadeada por um presidente eleito, Juan Bordaberry, teve as Forças Armadas como a instituição mais importante para o desenvolvimento do regime (GONZÁLEZ GUYER, 2007).

A ruptura institucional de 1933 representou o abandono do ideologia batllista. A crise política, acentuada pela morte de Jose Batlle y Ordóñez, em 1929, mesmo ano da débâcle econômica, levou 
a um golpe de Estado liderado pelo presidente Gabriel Terra, empossado em 1931. Sustentado somente pela Polícia Nacional, Gabriel Terra não contou com o apoio das Forças Armadas. Anos mais tarde, porém, elas tiveram uma participação importante na manutenção do sistema político, quando essas Forças foram chamadas para dissipar movimentos contestatórios armados, assumindo, pela primeira vez, a função repressora interna ao Estado.

Internamente ao setor castrense, é retomado o processo de maior profissionalização, justamente com a regulamentação das reformas já mencionadas. Durante todo o período ditatorial, é possível notar que as FFAA, em particular o exército, evoluem no sentido de consolidarem-se como instituição estatal com uma função específica. Rial (1986, p. 24-26) aponta que, já no início da década 1940, praticamente todo o corpo oficial do exército era proveniente de escolas militares. Assim, em 1941, com a Câmara dos Representantes reaberta, já foi possível promulgar a primeira Lei Orgânica do Exército que, ${ }^{5}$ dentro de outros aspectos, regulamentava a hierarquia interna e instituía os requisitos mínimos de ascensão na carreira. Estabelecia ainda um sistema educacional cujo intuito era possibilitar que o oficial assumisse várias funções, respeitando, ao mesmo tempo, o período mínimo de permanência em seus respectivos cargos.

Considerando, portanto, o período que se estende da construção do Estado até os anos 1970, as forças armadas tiveram pouca ou nenhuma participação política no Uruguai. Como mencionado, nem mesmo a ruptura institucional em 1933, modificou o comportamento militar. As forças armadas, pelas características próprias do sistema político, cujos partidos sempre procuraram manter os militares longe do poder - por exemplo, o único direito político que detém os fardados é o de serem eleitores -, ao mesmo tempo que Blancos e Colorados, partidos que agregam a elite hegemônica, mantém com eles estreita relação, há pouco espaço na caserna para extremismos que, agregado às características das próprias forças armadas (oficialidade não aristocrática, extensamente originada do meio rural, vendo a profissão das armas como mecanismo de ascensão social, que leva à baixa identificação de classe, etc.), contribui para a manutenção do comportamento institucional das forças armadas (LÓPEZ, 1995).

Pode-se dizer, então, que é a crise do próprio sistema político, da hegemonia das elites no poder, bem como a presença de novas regras no cenário internacional pós II Guerra Mundial, que geram as condições para que o militarismo se apresente no Uruguai na década de 1970. Outro exemplo a favor desta visão está na própria forma de implantação do regime autoritário no país: não houve um "momento brumário" (STEPAN, 1986, p. 102), um golpe de força, uma ruptura datada. Diferentemente de seus vizinhos, o autoritarismo não resultou de um levante militar, mas foi se impondo gradualmente, inclusive com amparo constitucional, e tendo como origem um governo civil democraticamente eleito (VILLALOBOS, 2006). 


\section{Um autoritarismo diferente}

Conforme definimos no início, militarismo significa um comportamento desviante das forças armadas, que deixam de cumprir sua missão precípua, a defesa da nação, para assumir outros papéis que, na maioria dos casos, confrontam a lei e a sociedade a qual devem servir. É tendo por base essa definição que julgamos o caso uruguaio como militarismo. Embora muitas vezes comparado com os demais regimes burocrático-autoritários que, a partir da ruptura de 1964 no Brasil se espalharam pela região, insistimos nas particularidades da ditadura estabelecida no Uruguai justamente para mostrar que se trata de um fenômeno bastante diferente.

Segundo Villalobos (2006), a crise que dá origem ao regime autoritário inicia-se no final dos anos 1950, agravada pela chegada do Partido Blanco ao poder (1959). Do ponto de vista interno, o país vivia sob uma nova Constituição (1952), que instituíra outra vez o sistema colegiado de governo, por meio do Conselho Nacional de Governo, incapaz, entretanto, de responder ao crescimento inflacionário, alta do desemprego, perdas salariais e ausência de um projeto político alternativo. Ao mesmo tempo, amplas parcelas da população sofriam com a falta de perspectivas, mormente os mais jovens. Tudo isso levou ao crescimento dos movimentos sociais contestatórios e, consequentemente, da violência repressiva do Estado.

À situação de crise interna somou-se a modelagem de um novo sistema internacional que, como é de amplo conhecimento, definia-se pelo clima da Guerra Fria, mormente depois da vitória da guerrilha cubana (1959). A nova concepção de segurança chegou ao Uruguai primeiramente pelas relações com o Brasil, mas amplamente sustentada pelos acordos militares estabelecidos com os EUA (Mello, 1996). A doutrina que garantiu esta nova percepção do inimigo nasceu da aprovação, pelo Congresso Americano, da lei de segurança mútua (1951), por sua vez consequência do Tratado de Assistência Recíproca (TIAR), aprovado em 1947 no âmbito da OEA (Villalobos, 2006, p. 44). Assim, com a Doutrina de Segurança Nacional iniciava-se o trabalho de educar os novos militares para defender não mais fronteiras físicas, mas ideológicas (COMBLIN, 1978).

No que se refere à sociedade uruguaia e sua relação com as Forças Armadas, essa não sofreu grandes alterações. O Exército mantinha-se bastante apartado da sociedade, limitando-se, muitas vezes às suas atividades nos quartéis e escolas de formação, praticamente inexistindo qualquer atividade de integração. Mesmo na década de 1950, quando há um retorno dos ideais batllistas, a distância entre a instituição militar e a sociedade chegou a tal ponto que a opinião pública em geral identificava as Forças Armadas como um órgão simbólico, sem força de combate e, principalmente, sem muita razão de ser, pois o até então vivia uma relativa paz na ordem interna e não tinha sérios motivos que preocupassem sua soberania, plenamente consolidada e garantida por diferentes tratados, inclusive o TIAR (RIAL,1986, p. 48). 
Por outro lado, a estrutura populacional do país contribuía para esse distanciamento. Dados de 1963, mostram que a população total do Uruguai era de 2.595 .510 habitantes; já a população urbana era de 2.101.378 habitantes, o que representa mais de $80 \%$. Destes, mais da metade viviam na cidade de Montevidéu (CELADE, 2005, p. 195). Entretanto, o recrutamento militar, além de endogênico, era feito nos extratos mais baixos da sociedade, principalmente jovens de comunidades rurais no interior do país. Esse aspecto dificultava ainda mais o envolvimento da classe média urbana de Montevidéu com as Forças Armadas. As palavras de Selva Lopez resumem a situação dos militares ao longo do período de crise hegemônica:

[...] o Uruguai oferece em seus níveis máximos a tensão sempre existente nos regimes liberal-democráticos entre as FFAA como garantia do poder do Estado e sua proclamada submissão ao mesmo, que há sido (sic.) definida como "o paradoxo do controlador-controlado". A falta de credibilidade da função externa capaz de gerar um consenso positivo para as FFAA na sociedade - e a sombra de ilegitimidade da missão interna em uma comunidade socializada nas linhas democráticas, se manifesta no "baixo perfil" da instituição militar no Uruguai nacional-reformista e mais adiante, quando o processo autoritário o eleva a níveis sem precedentes no país, na tendência a [ser encarado como] problema, constituílo como nenhum-tema e à utilização de estratégias quase sub-reptícias para a reprodução institucional (LOPEZ, 1995, p. 2).

Junta-se a isso as relações castrenses estabelecidas no âmbito externo, em particular com os EUA. Era nessa arena que se fornecia a função necessária que permitia às FFAA construírem (ou resgatarem) sua identidade: a elas cabia a defesa do Estado, o combate ao inimigo e este já não estava mais no exterior, não lutava a guerra clássica; ao contrário, estava no interior do país, mimetizando-se com a sociedade, cujo combate está no ato terrorista, no ataque indistinto e que não prevê campo de batalha. E além do suporte doutrinário, o contato com o exterior trazia modernização tecnológica para os quartéis.

A aproximação militar com os EUA, rendeu alguns acordos de cooperação militar, como o de 1952, cujo objetivo principal era promover a profissionalização e a atualização das Forças Armadas. Foram adotados, a partir de então, os manuais técnicos de combate bem como a organização interna das tropas, adaptada às condições uruguaias. Alguns militares foram convidados a participarem de treinamentos em conjunto, como a Armada que se juntou às tropas norte-americanas em um treinamento no Canal do Panamá. Um ano mais tarde, em 1953, a Armada Uruguaia passou a receber apoio técnico e equipamento dos norte-americanos.

$\mathrm{Na}$ formação doutrinária, boa parte dos oficiais de Estado-Maior passaram a ser treinados no Colégio Interamericano de Defesa, cujos bancos receberam grande parte dos militares conhecidos nos setores de informação e segurança dos regimes autoritários da América do Sul, sem esquecer aqueles dos países centro-americanos, que ajudaram a destruir as próprias forças armadas de seus países. Para não mencionar a destruição imposta às forças de defesa dos países centro-americanos 
(COMBELLAS, 1997). Data da mesma época a organização das Conferências Militares de Exércitos e de Inteligência, que incrementavam a difusão da doutrina de segurança nacional. Também funcionavam como uma espécie de órgão de "diplomacia paralela", pois nessas conferências se analisavam possíveis acordos entre Estados, mormente daqueles assumidos com os EUA (LÓPEZ, 1995). Por meio dessa doutrina, os militares passaram a olhar para si mesmos como o único ator responsável pela garantia da democracia e, consequentemente, a ter, para repetir Juan Linz, "a vã esperança de tornar mais democráticas às sociedades por vias não democráticas contribuiu frequentemente para o crescimento da crise de regime e, em última instância, prepararam o caminho para os governos autoritários" (ANEP, on line).

Essa situação encontrou terreno fértil para se desenvolver, pois a década de 1960 foi marcada pelo crescimento dos movimentos sociais ao mesmo tempo em que se fechavam canais partidários, ao colocarem na ilegalidade os partidos comunistas e/ou socialistas. Essa conjunção de fatores à crise econômica que assolava o país e, inevitavelmente, levava à perda de direitos sócioeconômicos proporcionados pelo welfare state uruguaio, teve como resposta o desenvolvimento progressivo da crise do sistema político (VILLALOBOS, 2006, p. 51). A conjuntura se complica ainda mais quando os movimentos sociais tomam a via armada, transformando-se em guerrilheiros, o principal deles agrupado sob o Movimento de Libertación Nacional - Tupamaros. ${ }^{6}$

À medida que a situação política foi se tornando mais crítica, com os partidos tradicionais respondendo com discursos, corrupção e ineficácia, maior era a força de movimentos opositores, como as Forças Armadas e a guerrilha. Por isso, não estranha o aumentando da participação militar na política, justificando-se como guardiãs do Estado e do progresso, além do aumento de sua atividade na repressão, dando corpo à doutrina de segurança nacional, na qual, relembrando, a principal função das Forças Armadas é o combate ao inimigo interno (COMBLIN, 1978). Gerou-se, assim, o ciclo vicioso que levou à eleição de Jorge Areco, representante da ala mais conservadora do Partido Colorado (LOPEZ, 1995, p. 30). A partir de sua posse, em dezembro de 1967, estava traçado o caminho, para parafrasear Ernesto Geisel, 'lento, gradual e seguro', que levou ao autoritarismo burocrático.

É importante sublinhar que nessa quadra histórica, nos anos 1960 inicio dos 1970, se desenvolve mais uma particularidade do posterior regime burocrático-autoritário: o envolvimento, treinamento e ação das FFAA como força repressiva data desta época e, portanto, anterior à chamada "guerra suja". Essa característica pavimenta o caminho para que o Estado seja, conforme muitos descrevem, sujeito do terrorismo, um movimento que parte do próprio poder público e atinge a totalidade da sociedade, isto é, o terrorismo de Estado (PADRÓS, 2008, p. 149). 


\section{Nasce o Militarismo}

O governo eleito assumiu sob a égide de uma Constituição renovada, promulgada no mesmo ano de 1967. Nela se restabelece a unidade da presidência da República, a qual concentra muito mais poderes do que tinha na Carta anterior, de 1952. Todavia, por quase todo o período da presidência de Jorge Areco, o Uruguai viveu sob decretos de exceção. Seu governo caracterizou-se também pelo nascimento da Frente Ampla (1971), partido que representava uma terceira via para a política uruguaia - porém, é declarado inimigo do Estado já no seu nascedouro e por isso posto na ilegalidade -, e pelo aprofundamento da participação das FFAA na repressão. Neste aspecto, é importante mencionar sua convocação em junho de 1968, para reprimir a oposição gerada pela adoção de medidas econômicas bastante amargas, bem como a edição do Decreto 566/1971, que subordinava as forças policiais às FFAA, bem como reestrutura os órgãos da cúpula militar, unificando os comandantes das diferentes armas em um único órgão, a Junta de Comandantes em Jefe.

Conforme estabelecido pela Constituição, em 1971 acontece um novo pleito para a escolha do presidente da República, no qual se elege o representante dos Colorados, Juan Maria Bordaberry, que assume em março de 1972. Diferente de seu antecessor, o presidente deseja controle das FFAA, fazendo-as voltar aos seus quartéis. Porém, o acirramento dos protestos sociais e o aprofundamento da crise econômica, leva o próprio Congresso a apelar para as FFAA. Após "um cruento atentado" promovido pelos Tupamaros, o governo baixa o Decreto 277/1972, que cria o "Estado de Guerra Interno", mecanismo jurídico que define as ações do presidente e das FFAA a partir de então, concentrando ainda mais poder em mãos militares. Em contrapartida, as ações castrenses levaram à prisão, morte ou exílio de praticamente toda a oposição e, por isso, desde fins daquele ano de 1972, os tupamaros deixaram de representar qualquer ameaça ao governo uruguaio (Altman, 2009, on line).

A derrota da guerrilha não esmoreceu a crença militar sobre a necessidade de sua participação política. Ao contrário, o uso permanente do decreto 277/1972 mostra o fracasso da tentativa de Borbaberry de buscar mecanismos do próprio governo para assumir o comando das FFAA, tentativa essa exemplificada pela nomeação em menos de dois anos, de três sucessivos ministros da Defesa, sendo sua última cartada a designação do general Atonio Francese, que já havia passado pelo mesmo ministério da Defesa e ocupado o do Interior no governo de Jorge Areco (Lopez, 1995, p. 34). No entanto, Exército e Força Aérea emitiram um comunicado afirmando não reconhecer a autoridade do general enquanto ministro, pois o mesmo teria como propósito a desarticulação das Forças Armadas e, ao mesmo tempo, indicavam suas intenções de "oferecer segurança para o desenvolvimento nacional" (Comunicado $\mathrm{n}^{\circ} 4$, on line). 
Ficava claro que as Forças Armadas não aceitavam voltar aos quartéis e ainda reivindicavam um lugar maior na vida política do país. Tal postura foi confirmada com a imposição do chamado Acordo de Boiso Lanza, ${ }^{7}$ que mantinha Bordaberry em seu cargo, mas transferia parte de seu poder aos militares (NUNES, 2005). O acordo outorgava às Forças Armadas a responsabilidade pela segurança do desenvolvimento nacional, regulava a participação militar nas atividades políticoadministrativas, e estabelecia o Conselho de Segurança Nacional (COSENA), órgão do Poder Executivo que tinha como principal função assessorar sobre as questões de Segurança - o que incluía assuntos econômicos e mesmo sociais - e cujos mentores estavam no setor castrense (Decreto163/1973). Pouco depois, criou-se também a Junta de Comandantes em Chefe das Forças Armadas e o Estado Maior Conjunto (Decreto 239, de abril de 1973).

Assinado em fevereiro, o Acordo Boiso Lanza garantiu certa tranquilidade no agitado cenário da República Oriental, mas por pouco tempo. Em junho de 1973, com o apoio e pressão das Forças Armadas, o presidente Bordaberry dissolveu a Câmara dos Senadores e dos Representantes, colocando em seu lugar o Conselho de Estado, órgão criado para reformar a Constituição; impôs censura aos meios de comunicação; prendeu ou demitiu diferentes funcionários do Estado; promoveu grande depuração nos meios militares, etc. Portanto, no processo de construção do militarismo, entrava-se em uma nova etapa, chamada de "ensaio fundacional", pois o regime instalado tinha como objetivo a manutenção do status quo (ANEP, on line).

Por essa época, a formação em nível de Estado-Maior e de especialização em Inteligência (alcunha para espionagem), tinha deixado de ter no Panamá seu principal destino, passando a ser realizada em países mais próximos, particularmente Brasil e Chile. No entanto, a mudança, ao que tudo indica, não implicou em novos currículos ou programas e, talvez, esse fosse ainda mais enfático no modo como tratava o inimigo interno, justamente porque desenvolvia regimes políticos bastante semelhantes. É provável que essa escolha se mostrasse, ao mesmo tempo, uma medida financeira e, ao mesmo tempo, o atendimento de incentivos dos norte-americanos que, parece, queriam criar uma imagem de desinteresse pelo aprofundamento de regimes burocrático-autoritários cada vez mais repressivos e, por isso, alvo de denúncias internacionais por desrespeito aos direitos humanos.

Ainda relativo à doutrina e às funções militares por ela sustentadas, o regulamento militar, estabelecido pela Lei de 1941, já estava há muito ultrapassado e vinha sendo constantemente desrespeitado. Para colocar um fim nisso, ao mesmo tempo que buscava mostrar o compromisso do governo, mas principalmente das FFAA com a democracia, promulgou-se, em 1974, uma nova Lei Orgânica Militar, na qual estavam os novos conceitos para a Segurança e Defesa nacional que, por sua vez, passariam a ser a justificativa legal para as ações das Forças Armadas nesse período. Essa lei, chamada Lei de Defesa Nacional, estabelecia que tudo o que fosse patrimônio uruguaio seria 
passível de intervenção armada por se enquadrar nas questões de segurança nacional. A Lei consolidou o COSENA como órgão articulador de políticas administrativas e criou ainda a Escola de Segurança e Defesa Nacional (ESEDENA). Seu principal objetivo era ideológico, ou seja, passar os novos princípios de Segurança Nacional para militares e civis.

Diferente de casos semelhantes na América do Sul, talvez para criar condições para a vigência da Lei de Defesa e ganhar apoio popular, as Forças Armadas cresceram nesse período, particularmente por meio de um intenso trabalho de recrutamento. Assim, os efetivos passaram dos 21 mil registrados em 1970, para mais de 38 mil em 1978. O mesmo aconteceu, ainda que em menor proporção, com os funcionários públicos civis, cujo número foi incrementado em cerca de 30\%, principalmente entre 1973-1976 (Lopez, 1985, anexos). O fato é que foi por meio da substituição de funcionários que a sociedade uruguaia percebeu estar sob um novo regime (ANEP, on line $).{ }^{8}$ Por outro lado, o arrocho salarial atingiu todas as categorias, ainda que as perdas tivessem sido menores para as FFAA.

Durante o período de “ensaio ditatorial” (1973-1976), também chamado de governo civilmilitar, o cenário político pode ser resumido nas seguintes características: a) Autonomia inquestionável das Forças Armadas em temas de segurança, inclusive segurança pública; b) controle das atividades estatais pelas Forças Armadas, até mesmo nas questões orçamentárias; c) controle do poder legislativo e uma forte influência militar no poder judiciário; d) atuação das Forças Armadas como partido político que veio a substituir os outros, sem ação depois do fechamento do Congresso, ${ }^{9}$ e e) elaboração de uma doutrina de traços próprios que, a princípio seria a condutora das ações das Forças Armadas, mas acabou se estendendo para toda a sociedade.

Relativamente às atividades repressivas, as quais diziam respeito à primeira e à última das características citadas, é importante destacar que nos primeiros três anos, as ações repressivas tinham como alvo dirigentes partidários e sindicais e, portanto, assinalavam para a sociedade que se tratava de "arrumar a casa", um momento autoritário necessário para garantir a democracia. Por isso, as mudanças processadas a partir de 1975, particularmente em relação aos alvos da repressão, foram percebidas como o abandono da ideia original, como a fundação do regime. É a partir desse último ano que se inicia o processo de construção do "terrorismo de Estado", pois paulatinamente o inimigo foi se amalgamando ao cidadão comum e, portanto, qualquer pessoa, fosse ou não ativa na política em qualquer de suas esferas, poderia ser atingida pelo braço armado do Estado. Além disso, como culminância do processo de terror e suas "requintadas práticas repressivas", o Estado necessitava, para evitar a cobrança internacional, dissociar-se das ações violentas, o que "gerou uma dupla operacionalidade estatal: modalidades repressivas legais e ilegais coexistiam e se complementavam" (PADRÓS, 2008, p. 157). 


\title{
Militarismo como regime
}

Tomando como referência a definição de O'Donnell (1990) para regimes burocráticoautoritários, pode-se dizer que foi em 1976, quando foram suspensas as eleições e o presidente Bordaberry foi deposto, que as FFAA assumiram, sem subterfúgios, a construção do novo regime. Além do controle direto do governo, a principal diferença entre esse período e o anterior assenta-se na forma como as FFAA agem qua governo e qua polícia. No primeiro caso, se promove uma divisão de tarefas entre as FFAA e, internamente a cada uma, entre as Armas. Embora a pretensão fosse manter a profissionalização das Forças, o resultado foi a multiplicação e confronto de tarefas (feudalização de tarefas públicas), além da esperada priorização do Exército relativamente às suas co-irmãs. Já no segundo, desenvolve-se uma "policização" da guerra que, além de contribuir ainda mais do que no primeiro caso para a quebra dos parâmetros profissionais das Forças, resulta na identificação do inimigo com o delinquente comum e, consequentemente, na passagem da "guerra interna" para a "guerra suja". Conforme análise autorizada:

\begin{abstract}
A identificação do "inimigo interno" como "delinquente comum" tende a equiparar a guerra contra a subversão à "luta contra o marginal" e, através dele, apagar os parâmetros convencionais e até mesmo éticos do enfrentamento convencional. Esta "policização" da guerra e das funções das Forças Armadas, permite a transformação da "guerra interna" em "guerra suja" [...] etapa de transformação do regime em verdadeiro "terrorismo de Estado" (ANEP, on line).
\end{abstract}

A forma como as FFAA lidaram com o poder político no Uruguai, fez com que Alfred Stepan (1988) as comparasse ao totalitarismo europeu. Isso porque, relativamente aos seus vizinhos, o regime implantado no país foi o que mais "deteve, intimidou e interrogou" seus cidadãos. Soma-se a isso o controle total que os militares tinham sobre toda a população do país (facilitado pelo seu pequeno tamanho), vigiando e interferindo na vida privada da população como nenhum outro de seus vizinhos; sua intenção era a absorção da sociedade pelo Estado e, portanto, a mudança buscada pelo regime dos militares era forjar uma nova cultura política, desenraizando a democracia e promovendo novos valores, determinados pela DSN. Justamente por representar um quefazer que está longe de integrar as funções castrenses, podemos dizer que este foi um período no qual vigorou o militarismo, pois as FFAA extrapolaram de sua tarefa de defesa do país para assumir o governo com todas as implicações que acarreta.

Do ponto de vista econômico, o Uruguai cresceu ao longo dos quatro anos seguintes, cerca de $5 \%$ ao ano, mas ao preço de enormes perdas sociais - conhecidas pelo aumento da imigração, concentração financeira sem precedentes e do crescimento quase quatro vezes da dívida externa em seis anos. Ainda assim, os militares qua governo não patrocinaram interesses particulares, cedendo a alguns quando eram convencidos de que se tratava de interesse para a segurança nacional. Isso 
permitiu ao regime legitimar-se, ao menos até que a crise externa (como o choque do petróleo) se instalasse.

A partir da segunda crise do petróleo, passa-se a buscar uma alternativa para legitimar o regime. A encontrada é a adoção de uma nova Constituição que deveria ser referendada pela população. No Plebiscito realizado em 1980, as FFAA esperavam ver legitimada sua intervenção. Contudo, embora o comparecimento tenha sido significativo, a nova Constituição não foi aprovada, pois o "não" totalizou 57,2\% dos votos válidos. Em consequência, as FFAA deveriam deixar o poder para que a democracia fosse restabelecida.

Para as FFAA, particularmente aquelas que estavam no governo, o resultado do plebiscito representou um golpe bastante duro, especialmente porque elas deveriam enfrentar o tema da violação dos direitos humanos, o que sempre procuram postergar, mas que exigem solução para a instalação da democracia (Serra, 2008, p. 102). A perda no Plebiscito também significava que os militares não foram suficientemente persuasivos para impor, pela força, uma nova cultura política na qual a ordem prevaleceria sobre o diálogo, este último inerente à democracia. No entanto, como o regime ainda detinha bastante controle político, social e econômico, tendo conseguido praticamente eliminar a oposição, as FFAA reverteram a situação a seu favor, sinalizando com a redemocratização do país.

Segundo a tipologia de O’Donnell e Schmitter (1988), pode-se avaliar a saída das FFAA do governo desde duas perspectivas, não necessariamente determinadas pelo setor castrense e nem escolhida pelos outros atores sociais, mas sim produto da disputa pelos vários atores e sua crença ou não na democracia como regime político. Quando os atores fardados são mais fortes ou há equilíbrio entre autoritários e democratas, a transição desde o regime autoritário realiza-se de forma negociada. Já quando as FFAA estão enfraquecidas ou o equilíbrio tende para os setores democráticos, a transição acontece por colapso ou por debandada (Saint-Pierre, 1994, p. 16). Casos de transição negociada são os mais conhecidos, estando nesse grupo Espanha, Brasil e Uruguai, entre outros. Já a Argentina é um caso traumático de ruptura.

É provável que o principal fator para a transição uruguaia ter sido negociada seja as poucas modificações ao sistema político impostas pelo regime autoritário, bem como a paciência das oposições em relação à "responsabilização" das FFAA pelo desrespeito aos direitos humanos. Conforme antes indicado, a Frente Ampla foi definida como inimigo pelas FFAA já no início da década de 1970, levando ao que foi nomeado como guerra anti-subversiva, impondo-se aos considerados subversivos o exílio ou o cárcere, em ambos os casos sendo tratados como delinquentes comuns (GONZÁLES GUYER, 2007, p. 98).

Ao contrário da transição brasileira, um aspecto muito importante na uruguaia é que enquanto a primeira representou a "fundação" de um regime partidário que pudesse sustentar a democracia - 
sequer sabia-se com quem negociar -, no Uruguai viveu-se a "restauração" da democracia. Esse fator é também fundamental para compreender como se pactuou entre civis e militares a transição para a democracia, bem como sua duração - as negociações se prolongaram por quatro anos, finalmente culminando no pacto do Clube Naval. A iniciativa foi dos militares e, embora o Partido Nacional não tenha aceitado negociar, pois um de seus líderes fora detido, esse pacto pavimentou a saída dos militares do governo.

A iniciativa partiu do meio castrense porque, entre outros fatores, no âmbito interno aos quartéis, a "partidarização" levou a divisões que contribuíram para o enfraquecimento das FFAA, incentivando-as a buscar um acordo que garantisse, ao mesmo tempo, um revestimento democrático com a permanência de alguma autoridade em mãos militares. A esse respeito, Sempol (2008, p.101), repetindo Achard, aponta dois grupos principais no interior das FFAA. Um deles, chamado "los políticos", tinha seu núcleo no exército e buscava criar um partido representativo do regime, o que representaria o continuísmo no poder. Já o outro, sob a insígnia de "profesionales", composto basicamente por militares da Armada e da Força Aérea, objetivava a saída das FFAA do poder da forma mais ordenada possível. Os últimos foram, naquele momento, vitoriosos.

Pelo acordo, os militares poderiam apresentar-se para as eleições de 1985 e as Forças Armadas ficariam incólumes, permanecendo todos os comandos em suas funções mesmo após as eleições de 1985, o que levou à pavimentação do caminho para o governo democrático com a eleição de Julio María Sanguinetti à presidência da República. De perfil palatável ao meio castrense, o presidente colorado acatou os interesses das FFAA e enviou ao Parlamento a chamada Lei da Caducidade da Pretensão Punitiva do Estado, que, aprovada, deixava livres e sem julgamento a quase totalidade dos maiores assassinos e torturadores do governo autoritário.

Outro aspecto do acordo foi a edição da figura jurídica que serviria como uma ferramenta de ação em caso de subversão ou insurreição durante o período de transição. Por meio da ação do COSEMA - que se transformara em órgão consultivo da presidência da República - poder-se-ia suprimir os direitos dos cidadãos e utilizar a justiça militar como forma de disciplinar os opositores. O controle dessa medida, no entanto, não ficou com os militares e sim com o Poder Legislativo.

A Lei de Caducidade foi adicionada à Lei Orgânica das Forças Armadas, sancionada em 1984. Para o que aqui interessa, a principal mudança foi a de remodelar a estrutura hierárquica das Forças Armadas, fazendo com que estas retornassem à sua forma piramidal, distorcida durante o período em que as Forças Armadas estiveram no poder. Como consequência, alguns militares de alta patente foram obrigados a passar para a reserva.

Com as garantias legais, iniciou-se uma nova fase, chamada por O’Donnell de governo democrático e capaz de representar o ponto final do militarismo uruguaio, ainda que não se tenha completado a transição para o regime democrático. Nessa nova fase, como resume González Guyer, 
“as relações entre Forças Armadas e Sociedade e sua dimensão central, a subordinação militar às autoridades democraticamente eleitas, constituem assunto de constante presença na agenda política do Uruguai desde a restauração institucional de 1985" (2007, p. 1000, grifos nossos). Isso porque, sem a completa subordinação militar às autoridades civis, o que exige também a revisão e punição do período de governo burocrático-autoritário, não se erige um verdadeiro regime democrático (id., ib., ib.)

O processo de revisão das atrocidades cometidas, cujo bloqueio não apenas deu-se pela Lei de 1985, mas também pela Lei de Validade da Pretensão Punitiva (1986), referendada pelos uruguaios em 1989, postergou indefinidamente um dos requisitos para a completa subordinação militar e, consequentemente, da restauração da democracia. Mesmo assim não se pode negar os avanços conquistados, como a experiência de um sistema partidário que inclui ao invés de dividir - passou do bipartidarismo para o multipartidarismo e, nas candidaturas do monopartidarismo para experimentar a coalizão -, ou o esforço para restaurar o Estado de bem estar que existira antes de 1976.

É possível dizer que ainda há um movimento de inversão histórica, iniciado com a chegada de Tabaré Vázquez à presidência da República, em 2005, pois, pela primeira vez depois de iniciada a transição, um candidato de oposição que fora perseguido e exilado pelo governo autoritário, chegou ao poder por meio do voto. Também foi esse representante da coalizão arregimentada pela Frente Ampla que buscou, ao longo de seu governo, alguma responsabilização castrense pelo desrespeito aos Direitos Humanos praticados pelas Forças Armadas na década de 1970, processo que ainda está em curso.

Em março de 2010, Vázquez entregou a faixa presidencial ao seu colega da Frente Ampla José Mujica, mostrando que a democracia deve vingar. Boa parte do sucesso do regime deve ser creditado à firmeza de seu sistema partidário que, se mudou, o fez para melhor. A mudança se fez na criação de novos partidos, vencendo o bi-partidarismo que se mostrou ineficiente para a renovação da democracia. Por isso, pode-se dizer que há uma outra democracia se consolidando no país, uma democracia fundada nos muitos partidos que atualmente povoam o cenário político uruguaio participando regularmente das eleições, como o Partido Independente, Liberal, Humanista, a coligação de movimentos sociais Assembleia Polular, entre outros.

No referente às FFAA, o presidente sempre sinaliza que, mesmo tendo sido grande os avanços na área de defesa, resta muito por fazer no âmbito das FFAA. Um aspecto recorrente na campanha do atual presidente foi a criação de mecanismos que consolidem ou aumentem a participação civil no controle das Forças Armadas. 


\section{Palavras Finais}

Ao longo desse texto, buscamos mostrar a diferença da atuação das FFAA no Uruguai, bem como o processo de constituição do sistema político do país em relação aos seus vizinhos. Se fomos felizes, o leitor terá percebido que há muito em comum entre os regimes burocrático-autoritários nascidos na America do Sul nos anos 1960 e 1970. No entanto, o que há de semelhante não basta para encobrir a singularidade do caso uruguaio.

Apontando algumas destas semelhanças, podemos destacar que no Uruguai, assim como no Chile, os partidos políticos ocupam o centro do poder e a partir daí se constrói o sistema político nacional, situação já observada antes da Segunda Guerra. Em seus respectivos períodos de militarismo, ambos os países demonstram um crescimento do contingente militar bem como uma modernização dos instrumentos militares. No entanto, o Uruguai não destina uma verba exclusiva para a manutenção de suas Forças Armadas, ao contrário do país andino.

No que se refere à Argentina, o fator comum é uma desorganização burocrática durante o período de governo burocrático-autoritário. A intenção de dividir os aparatos Estatais entre as Forças Armadas é apontada como o principal motivo desta desorganização. Diferente, porém, do caso argentino, no Uruguai as FFAA tiveram algum controle sobre sua saída do poder, o que aproxima este caso do brasileiro, no qual também houve controle militar sobre a transição, mas, no Uruguai, a saída castrense do governo foi negociada com os partidos tradicionais, os quais renasceram assim que tiveram a oportunidade.

Em resumo, pode-se afirmar que o Uruguai é caso único de construção precoce da democracia por meio da universalização do ensino. Porém, esta diferença não o afasta de seus visinhos, como pontuamos:

- À semelhança do Chile, são os partidos que ocupam o centro do poder em torno dos quais é construído todo o sistema político, fato ocorrido antes da II Grande Guerra;

- Ainda no que toca ao Chile, o Uruguai dele se aproxima no crescimento do contingente e na modernização dos meios (armamento) das FFAA ao longo dos anos de militarismo. Porém, ao contrário daquele, os uruguaios não têm uma verba exclusiva para a manutenção de suas FFAA;

- Em comum com a Argentina, o Uruguai vive seu regime burocrático-autoritário não apenas nos mesmos anos, como a forma de "lotear" o Estado entre as FFAA, o que representou uma desorganização da burocracia bastante forte;

- Diferente, porém, do caso argentino, no Uruguai as FFAA tiveram algum controle sobre sua saída do poder, o que aproxima esse caso do brasileiro, no qual também houve controle militar sobre a transição. Mas, no Uruguai, a saída castrense do governo foi negociada com os partidos tradicionais, que renasceram assim que tiveram a oportunidade; 
Poder-se-ia continuar pontuando as semelhanças, o que reforça a necessidade de análises comparadas. Todavia, o mais importante aqui é sublinhar que o caso uruguaio teve algumas singularidades, entre as quais imputamos como mais importantes: a forma gradual de constituição do militarismo no país, a aproximação do regime dos totalitarismos europeus com o desenvolvimento do "terror de Estado", mecanismo utilizado para destruir a cultura política prevalecente antes de 1976, e a persistência de um conjunto de regras democráticas capazes de informar que, em essência, e apesar do muito que se perdeu, a cultura política é a mesma, só que mais desenvolvida. Por último, lembramos que a legislação uruguaia relativamente às FFAA e à Defesa da Nação, sofreu pouca modificação ao longo dos últimos 30 anos. Quiçá se possa imputar o desenvolvimento desta cultura democrática à precocidade da educação como alicerce da cidadania, pois, como caso único, o Uruguai apresenta uma política de construção democrática baseada na educação, criando desde muito cedo, comparando-se com seus vizinhos, uma cultura política de forte apelo democrático.

\section{Referências Bibliográficas}

ALTMAN, M. Tupamaros foram guerrilla mais eficaz da América do Sul. In Opera Mundi, 25/10/09. Disponível em 〈http://operamundi.uol.com.br/noticias_ver.php? idConteudo=1730>. Acesso em 14/07/2010.

ANEP (Administración Nacional de Educación Publica). Medio siglo de História. Proyeto desarrollado por Dirección de Formación y Perfeccionamiento Docente, Área de Perfeccionamiento Docente y Estudios Superiores. Disponível em <http://www.anep.edu.uy/historia/>. Acesso em 14/07/2010.

ARTEAGA, J. J. Breve historia contemporánea de Uruguay. Cid. México, FCE, 1995.

CELADE. Boletím demográfico $n^{\circ} 75$ : América Latina: Urbanización y Evolución de la Población Urbana, 1950 -2000. Santiago, CEPAL, Janeiro, 2005. Disponível em <http://www.eclac.org/publicaciones/xml/6/21806/00BD75.pdf >. Acesso em 13/07/2010.

COMBELLAS, R. Democracia, Estado y sistema representativo. In Congreso Nacional \& Ministerio para el Enlace Ejecutivo y Congreso de la República de Venezuela (ed.). La integración y la democracia del futuro en América Latina. Caracas, Nueva Sociedad, pp. 87-96, 1997.

ESPINA, E. Historia Universal Del Uruguay. Montevidéu, Ed. Planeta, 2a . Edição, 2008.

GONZÁLEZ GUYER, J. Relações entre Forças Armadas e Sociedade no Uruguai: exercício comparativo com o Chile. In Saint-Pierre, H. (comp.) Controle civil sobre os militares e política de defesa na Argentina, no Brasil, no Chile e no Uruguai. São Paulo, Ed. UNESP, pp. 97-121, 2007.

LOPEZ, S. C. Uruguai 1985-1993: estratégia e tática da reprodução institucional militar na pósditadura. Tese de Doutorado em Ciências Sociais. IFCH-UNICAMP, 346 pp, 1995. (mimeo). 
COMUNICADO No 4", Mandos militares conjuntos del Ejército y la Fuerza Aérea, 9 de fevereiro de 1973. Disponível em <http://www.uc.org.uy/d0203b.htm>. Acesso em 05/07/2010.

NUNES, A.B. O bonapartismo uruguaio nos editoriais do Semanário Busqueda. Anais do I Simpósio do Grupo de Estudos de Política da América Latina (GEPAL). Londrina, UEL, setembro 2005. Disponível em <http://www.uel.br/grupo-pesquisa/gepal/primeirosimposio/completos/ antoniobezerranunes.pdf>. Acesso em 13/07/2010.

MELLO, L. I. A. Argentina e Brasil. A balança de poder no Cone Sul. São Paulo: Annablume, 1996.

MOREIRA, C. A esquerda no Uruguai e no Brasil: cultura política e desenvolvimento partidário. Opinião Publica vol. 6, nº 1. Campinas, UNICAMP, abr, 2000.

O’DONNELL, G. Análise do autoritarismo burocrático. Rio de Janeiro: Paz e Terra, 1990.

; SCHMITTER, P. Transições do Regime Autoritário: primeiras conclusões. São Paulo: Vértice, 1988.

PADRÓS, E. S. Repressão e violência: segurança nacional e terror de Estado nas ditaduras latinoamericanas. In Fico, C. et. al. (orgs.) Ditadura e Democracia na America Latina, balanço histórico e perspectivas. Rio de Janeiro, FGV, p. 143-178, 2008.

PASQUINO, G. Verbete Militarismo. In BOBBIO, N.; MATTEUCCI, N.; PASQUINO, G. (1986). Dicionário de Política. Brasília, UNB, pp. 748-754.

RIAL, J. Las Fuerzas Armadas: ¿soldados-políticos garantes de la democracia? Montevideo: Ediciones de la Banda Oriental, 1986.

RILLA, J. La tradición contra los partidos en el Uruguay. História (São Paulo), Franca, UNESP, 23 (1-2): 161-196, 2004.

SAINT-PIERRE, H. Prefácio. In MATHIAS, S.K. Distensão no Brasil: o projeto militar (19731979). Campinas, Papirus, p. 13-16, 1995.

SEMPOL, D. La historiografia blanca sobre el pasado reciente: entre el testimonio y la historia. In FICO, C. et.al. Ditadura e Democracia na America Latina (balanço histórico e perspectivas). Rio de Janeiro, FGV, pp. 95-116, 2008.

SERRA, N. La transición militar: reflexiones en torno a la reforma democrática de las fuerzas armadas. Barcelona: Randon House Mondadori, 2008.

SIERRA, G. Classes, Sistema Político e Estado no Uruguai do Primeiro Batllismo. In BRUIT, H. H. (org.). Estado Nacional e Burguesia na América Latina. Campinas, Ed. da Unicamp, 1985, p.131-160.

STEPAN, A. Os militares: da abertura à nova república. Rio de Janeiro: Paz e Terra, 1986. 1988. . Rethinking military politics, brazil and the Southern Cone. Princeton: Princeton University, 
VILLALOBOS, M.A. Tiranos, tremei! Ditadura e resistência popular no Uruguai (1968-1985). Porto Alegre: EDPUCRS, 2006.

\section{NOTAS}

${ }^{1}$ Resultado parcial do projeto "Educação militar e construção da Democracia", desenvolvido com bolsa CNPq-Pq 2009-RN 009/2009.

${ }^{2}$ Desde muito cedo, a elite que luta pelo poder no Uruguai se organiza entre Blancos - identificados com os federalistas argentinos - e Colorados, que defendem a organização unitária do Estado. Desde a independência do país, em 1825 e até o final da chamada "Grande Guerra" (1839-51), os chefes militares destes dois grupos, respectivamente Manuel Oribe e Fructuoso Rivera, buscaram afirmar-se no poder aliando-se aos federalistas (Blancos) e unitaristas (Colorados) argentinos. Embora tenham tido vitórias momentâneas, foi apenas com a intervenção externa, que impôs a visão de Montevidéu (Colorada) que se pôde iniciar o caminho de construção do país, preparando o terreno para as reformas que criaram a "Suíça americana". Cf. Arteaga, J. J. Breve historia contemporánea de Uruguay. Cid. México, FCE, 1995.

${ }^{3} \mathrm{O}$ título de Suíça sul-americana também foi dado ao Uruguai pelo namoro com o modelo suíço de governo, de poder executivo colegiado, como mais acima mencionamos.

${ }^{4}$ Conforme já mencionado, antes mesmo da Primeira Grande Guerra, a obrigatoriedade atingia o ensino médio, o que equivalia a aproximadamente 10 anos de ensino, muito maior do que os sistemas educacionais dos países da região, muitos dos quais não alcançaram, nem na primeira década do século XXI, o mesmo patamar de educação obrigatória.

${ }^{5} \mathrm{Na}$ mesma época, foi promulgada a Lei Orgânica da Marina Nacional, atualmente denominada Armada Nacional, cujo conteúdo era bastante semelhante àquela do Exército. Essas leis foram precedidas pelo Regulamento de Serviço, de 1921 que, como indica seu nome, tratava muito mais da lida militar interna aos quartéis do que das missões e funções das forças armadas (Lopez, 1995)

${ }^{6}$ O Movimento de Libertação Nacional - Tupamaros (de Tupac Amaru, nome de líder indígena que lutou contra a invasão espanhola no século XVII), nasceu no início da década de 1960 no meio rural, como representante dos trabalhadores de canaviais e da participação vários grupos da esquerda uruguaia sob coordenação do estudante Raul Sendic. A primeira ação importante do grupo foi a Marcha entre Bella União (Artigas), no norte do país, à Montevidéu, em 1962. Apesar da diversidade ideológica entre seus membros, a visão histórica marxista acabou prevalecendo como a ideologia do grupo. Sua atuação foi logo identificada com a Revolução Cubana de 1959, fato que teve forte influência em suas ações. O grupo organizou-se como uma guerrilha, já que não se vinculava, inicialmente, com nenhum partido político. A partir da década de 1980, com a reabertura democrática no Uruguai, o grupo passou a ser organizado politicamente sob uma coalizão de esquerda, ganhando status de um partido político (Villalobos, 2006, pp. 63-65).

${ }^{7}$ Nome dado em referência ao local no qual se elaborou o acordo, uma base da Força Aérea localizada nos arredores de Montevidéu.

${ }^{8}$ Conforme Lopez, “durante o regime militar os cidadãos foram classificados em categorias - A, B e C - de acordo de acordo com parâmetros de adesão-discrepância com a ordem estabelecida" (1995, p. 45, nota 61).

${ }^{9}$ As FFAA passaram a se comportar como partido político até para o seu próprio meio, isto é, os critérios de ascensão na carreira e de ocupação dos melhores postos no interior das Forças deixaram de ser determinados por parâmetros profissionais, como mérito e respeito à doutrina, e passaram a ser tomados critérios políticos, de adesão ou não à causa. Alguns autores defendem inclusive que critérios de divergência pessoal foram utilizados para expurgar as FFAA (ANEP, on line).

Artigo recebido em 10/2010. Aprovado em 11/2010. 